\section{NASA plans to upgrade the role of academics}

The National Aeronautics and Space Administration is planning a major effort to increase the involvement of academic scientists in all aspects of its research and development activities.

Dr Robert Frosch, the administrator of NASA, last week signed a policy statement stating that in future academic scientists will conduct "a substantial proportion" of the basic research in all disciplines involved in the agency's programmes.

Non-NASA scientists will in consequence be closely involved in all phases of the basic research activity, from the conception and planning of a particular project, through programming and execution, to the interpretation of data and the publication of research results.

According to the policy statement, which has not yet been officially released, the agency plans to increase the use of peer evaluation of research projects at regular intervals to guarantee that a high qualiy is maintained throughout its activities; continuing research programmes, for example, will be reviewed by peer evaluation at least once every three years.

In the past NASA has been criticised for conducting too much of its research, particularly in the more technological areas such as space applications, on an in-house basis, with little attempt at outside evaluation. It is hoped that one effect of the new policy, which is partly a response to a directive from President Carter that all government agencies should increase their support for basic science, will help to counteract many of these criticisms.

Although no extra money has, as yet, been made available, NASA is at present working on development plans to follow the space shuttle programme, whose research and development costs peak in 1980.

Each division of the agency has been asked to prepare a plan of its future proposed activities, taking the new policy statement into account. A fiveyear plan for the agency based on these proposals will then be published in the fall, and this is expected to indicate ways in which, as the shuttle programme tails off in cost, support for other areas - including academic science---can be increased with no net growth in the overall budget.

One division in which the new policy is likely to have a considerable effect is the Office of Space and Terrestrial

\section{Oceans ahoy: SEASAT-A to go aloft}

Seasat-a, a satellite designed to study the world's oceans from space, will-if all goes according to plan-be launched by the National Aeronautics and Space Administration from the Vandenberg Air Force Base in California next Monday, 26 June.

The satellite will circle the Earth 14 times a day, sending back information on surface winds and temperatures, currents, wave heights, ice conditions, ocean topography and coastal storm activity. $95 \%$ of the surface of the Earth's oceans will be covered by the satellite every 36 hours, and the data collected will be distributed to a wide range of users, including oil exploration firms, shipping companies, pollution control agencies and the weather services.

In addition to NASA, both the Canadian government's Centre for Remote Sensing and the European Space Agency will operate datareceiving stations, the former at St John's in Newfoundland, and the latter at Oakhanger, just outside London (ESA hopes eventually to establish a second station in the Canary Islands)

A number of scientific projects are being set up both to evaluate and determine the geophysical significance of the data-for example by comparing it to that being gathered by conventional surface-based techniquesand to feed it into current oceanographic studies. NASA has about a quarter of the 160 applications it had received from US scientists to conduct experiments using Seasat.

However Seasat-A is primarily a 'proof of concept' mission designed primarily to discover how effectively the microwave equipment which it carries-a scanning radiometer, a radar scatterometer, a synthetic

applications, a major growth area in NASA's budget which covers activities such as earth resources satellites (for example the LANDSAT series), weather observation and climate research.

In the past many of such programmes have essentially been technical exercises, in which the prime objective has been to test and develop means of data acquisition, with the scientific component being added on at a relatively late stage.

As a result, academic scientists have been excluded from the early planning stages, and have had to make the best they can of the data provided to them. Under the now system, it is planned

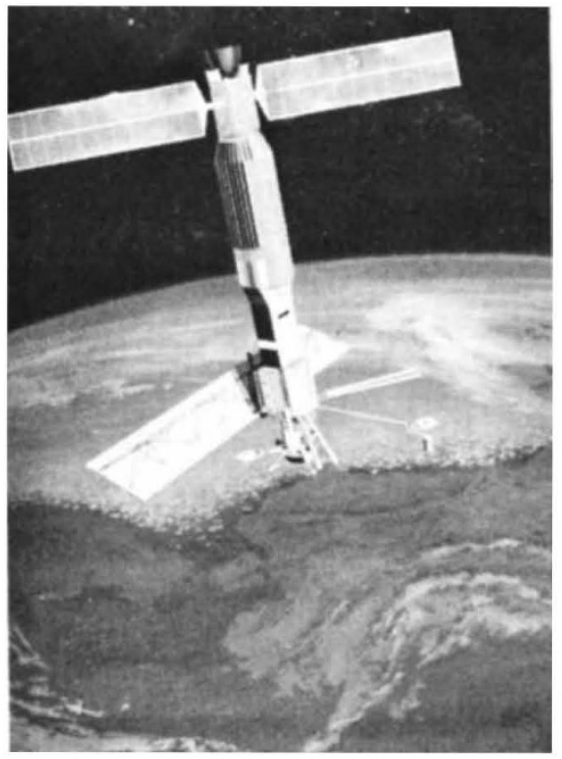

Artist's impression of SEASAT

aperture radar, and a radar altimeter - can provide useful scientific information for oceanographers, meterologists and commercial sea-users. The equipment also includes a visual and infrared radiometer which will provide information to support data from the microwave sensors.

At present Seasat-A is a one-off mission with no back-up-if the launch fails, work on a new satellite will have to begin almost from scratch. However if the mission is successful, NASA hopes to launch a follow-up satellite Seasat-B in 1983 from the Space Shuttle. Eventually the plan is to develop a multi-satellite network capable of monitoring the world's oceans on a continuous, realtime basis.

that there will be much closer contact between the scientific community there and instrument designers, and that the former will he closely involved in helping to decide the most useful type of data-both from a scientific and a "user" point of view-that a satellite should collect.

NASA officials stress that they see the importance of such close involvement of academic scientists as much in the quality control (which it is hoped that peer review and competition for grants will bring to the programme planning process) as in helping to develop specific fields of scientific knowledge.

David Dickson 